Article

\title{
Experimental Study of a Small Scale Hydraulic System for Mechanical Wind Energy Conversion into Heat
}

\author{
Tadas Zdankus *, Jurgita Cerneckiene, Andrius Jurelionis and Juozas Vaiciunas \\ Department of Building Energy Systems, Kaunas University of Technology, Kaunas 51367, Lithuania; \\ jurgita.cerneckiene@ktu.edu (J.C.); andrius.jurelionis@ktu.edu (A.J.); juozas.vaiciunas@ktu.edu (J.V.) \\ * Correspondence: tadas.zdankus@ktu.lt; Tel.: +370-37-300492
}

Academic Editors: Joanne Patterson and Derek Sinnott

Received: 17 May 2016; Accepted: 30 June 2016; Published: 20 July 2016

\begin{abstract}
Significant potential for reducing thermal energy consumption in buildings of moderate and cold climate countries lies within wind energy utilisation. Unlike solar irradiation, character of wind speeds in Central and Northern Europe correspond to the actual thermal energy demand in buildings. However, mechanical wind energy undergoes transformation into electrical energy before being actually used as thermal energy in most wind energy applications. The study presented in this paper deals with hydraulic systems, designed for small-scale applications to eliminate the intermediate energy transformation as it converts mechanical wind energy into heat directly. The prototype unit containing a pump, flow control valve, oil tank and piping was developed and tested under laboratory conditions. Results of the experiments showed that the prototype system is highly efficient and adjustable to a broad wind velocity range by modifying the definite hydraulic system resistance. Development of such small-scale replicable units has the potential to promote "bottom-up" solutions for the transition to a zero carbon society.
\end{abstract}

Keywords: low carbon technologies; energy efficient buildings; building heating; wind energy; heat generation; hydraulic system

\section{Introduction}

Wind power was the energy technology with the highest installation rate in Europe in 2015, accounting for $44 \%$ of all new installations [1]. The effective usage of wind energy is closely linked to sustainable development, energy independence and security on the regional scale, as well as global warming and $\mathrm{CO}_{2}$ emission reduction targets [2,3].

The vast majority of current European wind energy installations are large-scale variable speed wind energy conversion systems, designed for electrical energy production via doubly fed induction generators [4]. However, a high potential to reduce built environment related $\mathrm{CO}_{2}$ emissions lies within micro-generation technologies [5]. The main economic advantage provided by such wind energy systems, incorporated within the urban environment, is the location of the energy source close to the load [6]. In the case of Baltic States, a major part of total energy load in buildings is required to cover space heating and domestic hot water demand. For example, in Lithuania, thermal energy contributes to $58 \%$ of building energy demand [7-9], and this tendency is quite similar in other moderate and cold climate European countries. However, wind energy systems are used exclusively for electrical energy generation. This paper is focused on possibilities to use alternative or parallel conversion technologies which can be developed to contribute to smart energy management according to specific energy demand. Combining wind energy conversion into electricity and heat would allow reaching higher energy conversion efficiency for total energy supply systems and expand the application range of wind energy technologies. 
Regular misbalance between energy generation and demand is common for the majority of renewable energy applications $[10,11]$. Cost of batteries for electrical energy storage vary in the range from 300 to $3500 \mathrm{USD} / \mathrm{kW}$ [12]. Therefore, direct wind energy conversion into heat has its benefits from this point of view, as it provides a solution less sensitive to wind fluctuations by utilising thermal inertia of the heating system and the building itself [13]. Lower investment costs are required for thermal energy storage coupled with such systems, compared to electrical energy storage systems, and residential hot water storage solutions can be applied.

Nevertheless, it is important to note that this article is not intended to question the role of wind energy conversion into electrical energy. Thermal energy can be substituted by electricity in most applications; therefore, electrical energy will undoubtedly remain tightly linked with renewables and will play the most important role in transition to a zero carbon society.

According to current guidelines concerning both energy efficiency of buildings and renewable energy applications, direct wind energy conversion into heat is not considered, and no such devices are present in the mass market [14]. However, as energy demand for heating of buildings is decreasing within recent decades due to increased energy performance of buildings, renewable energy sources can cover the major part of modern building energy loads. For example, under the Lithuanian climate conditions, wind power plants of $2 \mathrm{~kW}$ heating capacity can cover from $40 \%$ to $76 \%$ of annual heating load of the medium size residential house, subject to its energy efficiency class [15].

Devices for wind mechanical energy conversion into heat by using hydraulic systems and mixers have been proposed and/or patented few decades ago [16-18]. However, commercial products were not developed and practical applications are currently non-existent in the market. However, in moderate and cold climate European countries, where wind speeds correspond to the actual thermal energy demand in buildings $[19,20]$; therefore, using wind energy systems for thermal energy production could supplement wind driven electrical energy generation systems and could reduce the demand for energy storage.

The technology of wind energy conversion into heat, discussed in this paper, is based on friction between fluid and solid material and can be described according to the classical fluid mechanics laws. Fluid temperature increase is often observed in the hydraulic drives due to fluid flows through various valves or throttles [21-23]. High-temperature oil operation has a damaging effect on hydraulic components; therefore, oil cooling is usually applied [21]. Similar effects can be observed in hydronic heating systems as water circulation in closed loop results in water temperature increase. Mechanical energy conversion into heat as a result of friction and local hydraulic losses is behind both of these examples.

The prototype hydraulic system containing a pump, flow control valve, oil tank and piping was developed for this study, utilising the effects described above. As the energy source of such hydraulic systems is the cost-free wind energy, such systems can provide effective small-scale low investment and maintenance cost solutions, to be applied in urban neighbourhoods. Issues to be considered to keep such systems within the reasonable investment costs are intermittency and turbulence of wind velocities in urban environments, as well as mechanical and aerodynamic noise from wind turbines $[24,25]$. In this study, average wind velocities were analysed and the wind turbine itself was simulated by using three-phase asynchronous four pole electromotor. The rest of the system was the actual prototype for direct electromotor generated mechanical energy conversion into heat. Detailed description of the system and experiment design is presented in Section 2.

This paper was mainly focused on the performance of the hydraulic system itself, by analysing heat output generated at different wind velocity ranges and optimising the hydraulic system work by changing the resistance of the hydraulic system.

Results of the experiments showed that the prototype system for direct wind energy conversion into heat is highly efficient and adjustable to broad wind velocity range. Therefore, it can become a replicable small-scale wind energy utilisation solution in the Baltic States region as well as other moderate and cold climate European countries at urban wind velocities [20]. 


\section{Materials and Methods}

\subsection{Experimental Setup}

The prototype hydraulic system for mechanical wind energy conversion into heat was designed for the experimental analysis. Mechanical wind energy was simulated by using the electromotor. Hydraulic system consisted of the oil tank, hydraulic pump, pressure (supply) pipe, flow control valve, copper tube heat exchanger, and return pipe. The foamed polyethylene thermal insulation was used for piping to minimize the heat losses. Experimental setup is presented in Figure 1.

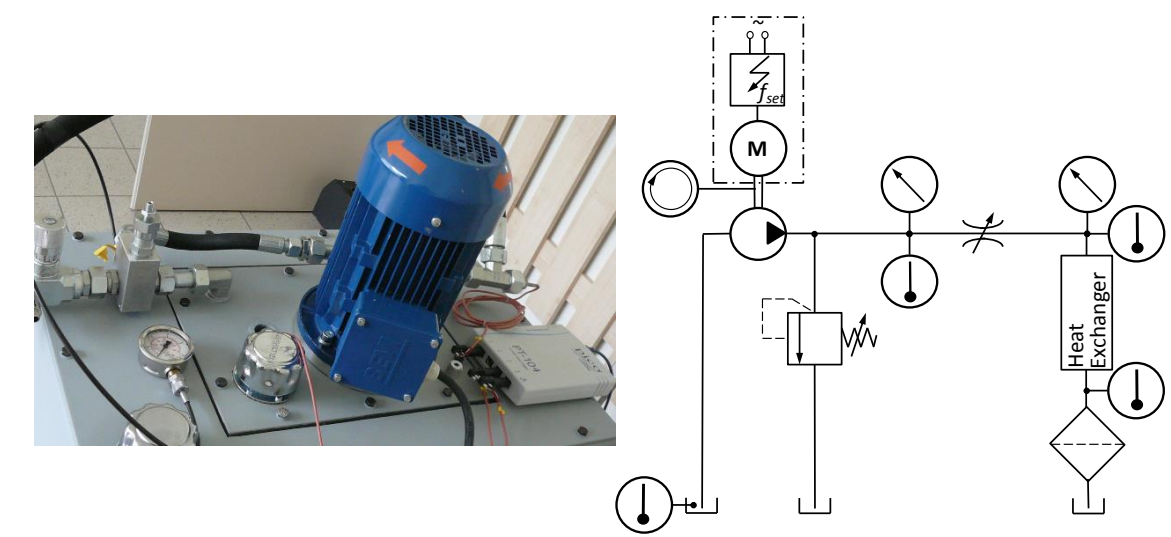

Figure 1. Photo and schematic view of the experimental setup.

Three-phase asynchronous, four pole electromotor 4AK2 90L-4B14 (Bevi, Blomstemåla, Sweden) with the power of $1.5 \mathrm{~kW}, \cos \varphi=0.77, \eta_{\text {motor }}=0.828$ was used for simulation of the rotational motion with transmission. Electromotor was calibrated (Figure 2) in the laboratory by using the torque sensor DR-2512 (Lorenz Messtechnik, Alfdorf, Germany).

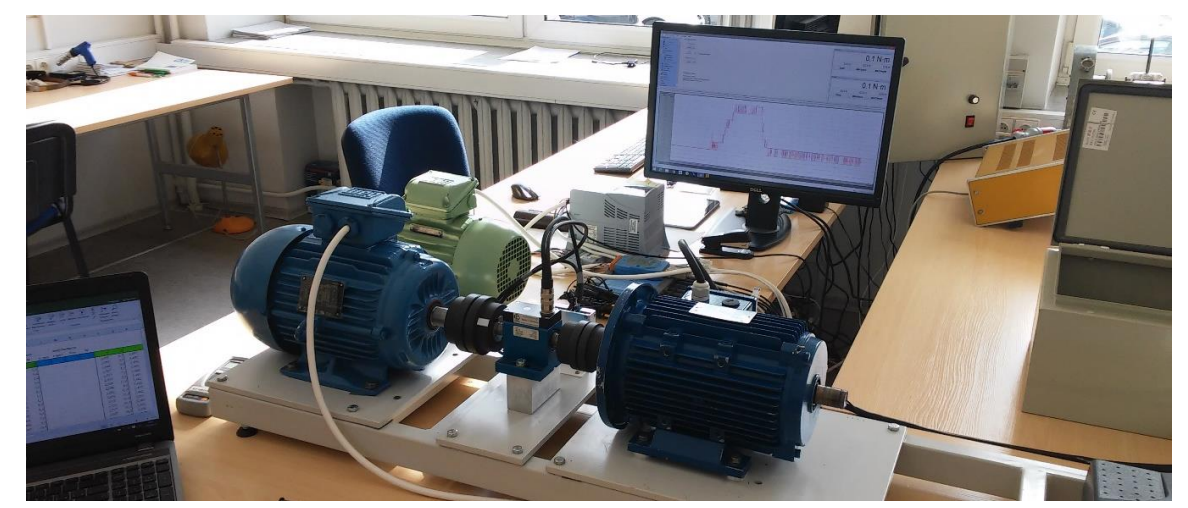

Figure 2. Electromotor calibration setup.

The aim of the calibration was to determine the highest possible output power of the electromotor $P_{m \_ \text {out }}$ for different electric frequency input $f_{\text {set }}$. Shaft rotation frequency of the electromotor followed the $n_{\text {set }}=f_{\text {set }} / 2$ rule, as a four pole electromotor was used. Calibration results are provided in Table 1 .

Rotation frequency of the shaft of the electromotor was changed by the three-phase, $1.5 \mathrm{~kW}$, $0.2 \div 400 \mathrm{~Hz}$ electric frequency converter FR-D740-036SC-EC (Mitsubishi Electric, Tokyo, Japan). The settings of the frequency converter, such as output frequency $f_{\text {set }}$, voltage and amperage were registered during the experiments.

Fluids circulated in the closed hydraulic loop, passing flow control valve installed in the pressure pipe, followed by the heat exchanger, and the returning oil tank. The electromotor was mounted 
in a vertical shaft position on the cover of the oil tank, and its shaft was connected to the shaft of the hydraulic pump via the rigid coupling. The hydraulic gear pump X2P5702 (Vivolo, Budrio, Italy) $-V_{p}=26.2 \mathrm{~cm}^{3} /$ rot., was used for the study. The hydraulic pump had been fully submerged into oil in the rectangular steel oil tank BEK 20/E/E (KTR, Germany) $-0.40 \times 0.298 \times 0.27 \mathrm{~m}^{3}$, wall thickness $\delta=4 \mathrm{~mm}$. The system was filled with 201 of hydraulic oil Tellus S2 M 46 (Shell, The Hague, the Netherlands)-ISO 3448 viscosity degree $46, \rho_{15}{ }^{\circ} \mathrm{C}=879 \mathrm{~kg} / \mathrm{m}^{3}, v_{20}{ }^{\circ} \mathrm{C}=104 \mathrm{cSt}$, $c=1.67 \mathrm{~kJ} /(\mathrm{kg} \cdot \mathrm{K})$. Internal diameters of the pump pressure pipe, as well as the pipes of the hydraulic system, heat exchanger and valve's connections were equal to: $d=20 \mathrm{~mm}$. Oil tank, pipes, housing of the flow control valve were thermally insulated by using polystyrene foam.

Table 1. Results of the electromotor calibration.

\begin{tabular}{ccccccccc}
\hline$n_{\text {set }}, \mathrm{Hz}$ & 0.5 & 1 & 1.5 & 2 & 2.5 & 3 & 3.5 & 4 \\
\hline$P_{m_{\_} \text {out }}, \mathrm{W}$ & 4.7 & 16.3 & 28.4 & 44.5 & 59.4 & 74.2 & 84.6 & 100.7 \\
\hline$n_{\text {set }}, \mathrm{Hz}$ & 5 & 6 & 7 & 8 & 10 & 15 & 20 & 25 \\
\hline$P_{m_{-} \text {out }}, \mathrm{W}$ & 122.5 & 159.9 & 193.8 & 233.0 & 305.9 & 518.1 & 728.7 & 959.8 \\
\hline & $n_{\text {set }}:$ electromotor shaft rotation frequency, $\mathrm{Hz} ; P_{m_{-} \text {out }}:$ hydraulic pump's input power, W.
\end{tabular}

The flow control valve worked as a load regulation valve. The loading of the hydraulic system was changed by decreasing the permeability of the flow control valve. The flow regulator valve VRFB $90^{\circ} \frac{3}{4}$ " (Contarini, Lugo, Italy) was used for hydraulic system loading and energy conversion. Valve opening degree $\gamma$ parameter was used for description of the valve opening position $\varphi: \gamma=\varphi / \varphi_{\max }$. Opening position of the valve was changed by the revolutions from the fully opened position $\varphi_{\max }=9$ rev. $(\gamma=1)$ up to the fully closed position $\varphi=0$ rev. $(\gamma=0)$. The least change of the valve opening position was: $\varphi=0.05 \mathrm{rev}$. Oil pressure after the pump $p_{1}$ was measured by the pressure sensor NAH 8253.83.2317 25.0 A (Trafag, Bubikon, Switzerland) $-0 \div 25$ bar, $4 \div 20 \mathrm{~mA}$, precision $0.3 \%$, and the pressure after load control valve $p_{2}$ was measured by the pressure sensor NAH 8253.75.2317 2.5 A-0 $\div 2.5$ bar, $4 \div 20 \mathrm{~mA}$, precision $0.3 \%$. To visualize the data obtained by means of the pressure sensors, two programmable meters N20-6112008 (Lumel, Zielona Góra, Poland) were installed. The values registered by the meters were periodically monitored and recorded.

The rotation frequency of the shaft of the electromotor $n$ was measured by the tachometer Testo 465 (Testo, Lenzkirch, Germany)—tolerance: $0.01 \mathrm{rpm}$.

Oil temperature was measured by platinum resistance thermometers TJ4-Pt100 (Auregis, Kaunas, Lithuania) of precision class ${ }^{1} /{ }_{3} \mathrm{~B}$ in six points: in the oil tank (three points), before the valve, before and behind the heat exchanger (Figure 1). A high-resolution temperature converter and data logger PT-104 (Pico Technology, Cambridgeshire, UK) and a personal computer were used for reading and storing the temperature data. Oil temperature was equal to $20 \div 21^{\circ} \mathrm{C}$ at the beginning of each experiment. A safety valve was installed for safe operation of the experimental setup; however, the limited pressure conditions during the experiments were not exceeded.

In order to check the reproducibility and reliability of the results of the experimental study, the statistical parameters were calculated for every test series performed at the same conditions. Cochran criteria $\left(C_{j} \leqslant 0.684\right.$ for four data series and degree of freedom equal to 3$)$, variation coefficient $(\mathrm{CV} \leqslant 5 \%)$ and general relative error $\left(\mathrm{C}_{\mathrm{err}} \leqslant 5 \%\right)$ were calculated. The values obtained did not exceed the threshold; therefore, the results of the experiments were considered reliable and reproducible.

\subsection{Experimental Methodology}

Wind turbine's output power $P_{w}$ depends on the cube of wind velocity $v$, rotor swept area $A$, air density $\rho$ and the power coefficient $c_{P}$ :

$$
P_{w}=c_{P} \frac{1}{2} \rho_{a i r} A v^{3}
$$


According to the Betz law [26], the theoretical maximum amount of power that can be extracted from wind is equal to $59.26 \%\left(c_{P_{-} \max }=16 / 27\right)$. A wind rotor with transmission was simulated in this study. The assumption was made that rotor swept area is equal to $10 \mathrm{~m}^{2}$ and the coefficient $c_{P}=0.45$. An average annual air temperature in Lithuania is equal to $5.5 \div 7.5^{\circ} \mathrm{C}$ [27] and air density is equal to $\rho=1.26 \mathrm{~kg} / \mathrm{m}^{3}$ [28]. Considering the rotor with transmission, simulated wind velocity was calculated according to the electromotor calibration results $P_{w}=P_{m_{-} \text {out }}$ for each output frequency of the converter $n_{\text {set }}$ by Equation (1) (Tables 1 and 2).

Table 2. Comparison of simulated experimental wind conditions and regional wind data for the Baltic States region.

\begin{tabular}{|c|c|c|c|c|c|c|c|c|}
\hline$n_{\text {set }}, \mathrm{Hz}$ & 0.5 & 1 & 1.5 & 2 & 2.5 & 3 & 3.5 & 4 \\
\hline$v^{*}, m / s$ & 1.18 & 1.79 & 2.16 & 2.50 & 2.76 & 2.97 & 3.10 & 3.29 \\
\hline Lithuania/average $v, \mathrm{~m} / \mathrm{s}$ & \multicolumn{8}{|c|}{$2.52 \div 4.55$} \\
\hline Latvia/average $v, \mathrm{~m} / \mathrm{s}$ & \multicolumn{8}{|c|}{$2.68 \div 4.22$} \\
\hline Estonia/average $v, \mathrm{~m} / \mathrm{s}$ & \multicolumn{8}{|c|}{$3.95 \div 6.86$} \\
\hline$n_{\text {set }}, \mathrm{Hz}$ & 5 & 6 & 7 & 8 & 10 & 15 & 20 & 25 \\
\hline$v^{*}, m / s$ & 3.51 & 3.83 & 4.09 & 4.35 & 4.76 & 5.67 & 6.36 & 6.97 \\
\hline Lithuania/average $v, \mathrm{~m} / \mathrm{s}$ & \multicolumn{8}{|c|}{$2.52 \div 4.55$} \\
\hline Latvia/average $v, \mathrm{~m} / \mathrm{s}$ & \multicolumn{8}{|c|}{$2.68 \div 4.22$} \\
\hline Estonia/average $v, \mathrm{~m} / \mathrm{s}$ & \multicolumn{8}{|c|}{$3.95 \div 6.86$} \\
\hline
\end{tabular}

$n_{\text {set }}:$ electromotor shaft rotation frequency, $\mathrm{Hz} ; \mathrm{v}$ : wind velocity, $\mathrm{m} / \mathrm{s} ;{ }^{*}:$ wind velocity corresponding to $10 \mathrm{~m}^{2}$ swept area wind rotor with conversion efficiency of 0.45 (this denotation is valid for the whole study).

Hydraulic system input power $P_{h{ }_{-} \text {in }}$ is equivalent to hydraulic pump's input power $P_{p_{-} i n}$ received from the electromotor $P_{h s_{-} \text {in }}=P_{p_{-} \text {in }}=P_{m_{-} \text {out }}$ and depends on shaft rotation frequency $n$ and torque $M$ :

$$
P_{h s \_i n}=2 \pi n M
$$

There were not any actuators in the hydraulic system; therefore, the whole mechanical energy losses in the pump, load control valve, pipes and heat exchanger converts into the thermal energy (heat):

$$
P_{h s_{i} i n}=P_{T l}+P_{T p}+P_{T f}
$$

where $P_{T l}$ is the thermal power generated in load regulation valve (adjustable component), $P_{T p}$ is the thermal power generated in the pump (non-adjustable component) and $P_{T f}$ is the thermal power from hydraulic losses in pipes and heat exchanger (non-adjustable component). $P_{T f}$ depends on the length of the pipes and the design of the heat exchanger and can be computed by Darcy-Weisbach and local losses formulas.

Thermal power losses to the outside of the system $P_{T_{-} l o s s}$ has an impact on thermal power output of hydraulic system $P_{h s_{-} \text {out }}$ :

$$
P_{\text {hs_out }}=P_{T}-P_{T_{-} \text {loss }}
$$

where $P_{T}$ is the amount of thermal power generated in hydraulic system: $P_{T}=P_{T p}+P_{T l}+P_{T f} . P_{T}$ can be defined as useful thermal power, which can be used for heat exchange or accumulation in the reservoir.

Equation (4) can be expressed as heat balance equation:

$$
m_{r} c\left(T_{r}-T_{r 0}\right)=\eta_{p V} n V_{p} \rho c\left(T_{\text {out }}-T_{r}\right) t-P_{T_{-} \text {loss }} t
$$

where $m_{r}$-oil mass in the reservoir, $\mathrm{kg}, \mathrm{c}$ - specific heat capacity of oil, $\mathrm{J} /(\mathrm{kg} \cdot \mathrm{K}), \rho$ —oil density, $\mathrm{kg} / \mathrm{m}^{3}$, $\eta_{p V}$ - pump volumetric efficiency coefficient, $T$-oil temperatures: in the reservoir $T_{r}$, in the returning 
pipe after the heat exchanger $T_{\text {out }}$ and the initial temperature of the oil in the tank $T_{r 0}, \mathrm{~K}$; $t$ - time interval, s.

Thermal power $P_{T}$ :

$$
P_{T}=\eta_{p V} \quad n \quad V_{p} \quad \rho c c\left(T_{\text {out }}-T_{r}\right) .
$$

$P_{T l}$ was chosen to analyse the primary optimal performance of the hydraulic system. Changing the opening degree $\gamma$ of the valve allows for controlling the amount of heat that can be generated in the hydraulic system. The amount of generated thermal power can be expressed:

$$
P_{T l}=\Delta p Q
$$

where $\Delta p$ is the pressure drop in the valve, $\mathrm{Pa}$; $Q$ is the volumetric flow rate of oil, $\mathrm{m}^{3} / \mathrm{s}$.

Pressure drop $\Delta p$ can be expressed as the local hydraulic losses in the load regulation valve:

$$
\Delta p=\frac{1}{2} \rho \zeta w^{2}
$$

where $\zeta$ is local loss coefficient of the valve; $w$ is the mean oil velocity, $\mathrm{m} / \mathrm{s}$.

The value of the local losses coefficient $\zeta$ was modified by adjusting the load regulation valve during the experiments. The opening degree of the valve $\gamma$ means the quantity of the hydraulic system load: $\zeta=f(\gamma)$. The volumetric flow rate $Q$ can be expressed according to the pump's parameters: rotation frequency $n$, nominal displacement $V_{p}$ and volumetric efficiency coefficient $\eta_{p V}: Q=n V_{p} \eta_{p V}$. The mean velocity of the oil $(w): w=4 Q /\left(\pi d^{2}\right)$. Thermal power of the load regulation valve can be calculated:

$$
P_{T l}=8 \rho \frac{\eta_{p V}^{3} V_{p}^{3}}{\pi^{2} d^{4}} \zeta n^{3}
$$

The efficiency of the hydraulic system for thermal energy conversion (Equations (2)-(4)): $\eta_{h s}=P_{h s_{-} \text {out }} / P_{h s_{-} i n}$, depends only on the heat losses to the outside:

$$
\eta_{h s}=\frac{P_{T}-P_{T \_l o s s}}{P_{h s \_ \text {in }}}
$$

If the heat losses could be decreased to the minimum $\left(P_{T \_l o s s} \rightarrow 0\right)$, the efficiency of thermal energy generating hydraulic system could be increased to the maximum $\left(\eta_{h s} \rightarrow 1\right)$.

\section{Results}

\subsection{Mechanical Energy Simulation}

The experimental setup was designed for simulating and analysing the operation of the wind driven hydraulic system. Wind performance as mechanical energy source was simulated under laboratory conditions by using $1.5 \mathrm{~kW}$ power electromotor and frequency converter without a feedback. Mechanical characteristics (torque $\mathrm{M}$ ) of the installed electromotor were determined and the peak power $P_{\mathrm{m} \_o u t}$ for different electromotor shaft rotation frequency $n_{\text {set }}$ are presented in Table 1 .

As the electromotor is tightly connected to the hydraulic pump, its further mechanical power $P_{\mathrm{m} \_ \text {out }}$ was treated as input power $P_{\mathrm{hs} \_ \text {in }}$ of the hydraulic system.

Different $n_{\text {set }}$ values can be related to performance of notional wind rotor under different wind speeds. Characteristics of the notional wind rotor was defined as a unit of $10 \mathrm{~m}^{2}$ swept area and 0.45 energy conversion efficiency. In subsequent calculations and discussions, correlation of energy produced with wind speed is strictly subject to this assumption, as thermal energy output of the system as well as corresponding wind speed depends on the technical parameters of the wind rotor.

Results of the corresponding wind speed $v$ calculation by using different $n_{\text {set }}$ values, as well as its comparison to the Baltic States region wind data are presented Table 2. Annual average wind speed registered by national met-office stations at $10 \mathrm{~m}$ height with terrain of 2 nd roughness class was used 
for comparison provided in Table 2 [19]. However, the actual performance of the hydraulic system presented in this study depends on the wind rotor type and wind speed in the particular location.

\subsection{Thermal Energy Generation}

Series of experiments were performed and the input electric power frequency of electromotor $n_{\text {set }}=$ const was determined and maintained at the required level by using the frequency converter. Rotation frequency of the hydraulic pump shaft $n$, oil pressure drop $\Delta p$ before and after the load regulation valve were measured and the flow rate $Q$ was calculated for each case.

Each experimental series was started from the minimal load and minimal resistance of the hydraulic system with load regulation valve fully opened: $\gamma=1$. Load regulation valve was closed gradually up to fully closed valve: $\gamma \rightarrow 0$. System performance regimes analysed in this study are presented in Table 3.

Table 3. Analysed regimes of hydraulic system performance.

\begin{tabular}{cccccc}
\hline No. & $\begin{array}{c}\text { Working Regime } \\
\text { of the System }\end{array}$ & $\begin{array}{c}\text { Opening } \\
\text { Degree of the } \\
\text { Valve, } \gamma\end{array}$ & $\begin{array}{c}\text { Rotation } \\
\text { Frequency, } \boldsymbol{n} \\
\text { and Torque, } \boldsymbol{M}\end{array}$ & $\begin{array}{c}\text { Pressure } \\
\text { Drop, } \Delta p\end{array}$ & Flow Rate, $Q$ \\
\hline 1 & Unloaded system & $\gamma=1$ & $\begin{array}{c}n=n_{\max } \\
M \approx 0\end{array}$ & $\Delta p \approx 0$ & $Q=Q_{\max }$ \\
\hline 2 & System loading & $\begin{array}{c}\gamma \rightarrow \gamma_{\mathrm{opt}} \\
(0<\gamma<1)\end{array}$ & $\begin{array}{c}n \rightarrow n_{\mathrm{opt}} \\
M \rightarrow M_{\mathrm{opt}}\end{array}$ & $\Delta p \rightarrow \Delta p_{\mathrm{opt}}$ & $Q \rightarrow Q_{\mathrm{opt}}$ \\
\hline $\begin{array}{c}\text { Rated } \\
\text { regime(optimal } \\
\text { performance) }\end{array}$ & $\gamma=\gamma_{\mathrm{opt}}$ & $\begin{array}{c}n=n_{\mathrm{opt}} \\
M=M_{\mathrm{opt}}\end{array}$ & $\Delta p=\Delta p_{\mathrm{opt}}$ & $Q=Q_{\mathrm{opt}}$ \\
\hline 5 & System overloading & $\begin{array}{c}\gamma \rightarrow 0 \\
(0<\gamma<1)\end{array}$ & $\begin{array}{c}n \rightarrow 0 \\
M \rightarrow M_{\max } \\
n \approx 0\end{array}$ & $\Delta p \rightarrow \Delta p_{\text {max }}$ & $Q \rightarrow 0$ \\
\hline$\gamma$ & Overloaded system & $\gamma \approx 0$ & $\Delta p \downarrow$ & $Q \approx 0$ \\
\hline
\end{tabular}

$\gamma$ : opening degree of the load regulation valve, dimensionless; $n$ : pump shaft rotation frequency, $\mathrm{Hz} ; \mathrm{M}$ : torque, $\mathrm{N} \cdot \mathrm{m} ; \Delta p$ : pressure drop, $\mathrm{Pa} ; \mathrm{Q}$ : volumetric flow rate, $\mathrm{m}^{3} / \mathrm{s}$.

The rotation frequency $n$ of the hydraulic pump shaft and flow rate $Q$ decreased until the peak point was reached followed by decrement of these parameters as the system was overloaded and stopped. Such hydraulic system overload can be utilised as a hydraulic brake and is adaptable in wind energy applications to stop the wind rotor in the case of extreme climate conditions.

The load control valve was the main heat generator in the hydraulic system. Therefore, the heat generation ability $P_{T l}$ of the valve was tested experimentally by measuring the pressure drop and the flow rate (Equation (7)). Dependence of $P_{T l}$ on opening degree of the load control valve $\gamma$ was determined.

Rated (optimal) regime was identified by the peak value of $P_{T l}$, and the optimal valve opening position $\left(\gamma=\gamma_{o p t}\right)$ and rotation frequency of the shaft $\left(n=n_{\text {opt }}\right)$ was registered for each case. Parameters of the rated regime were used to estimate thermal performance of the system.

Sixteen test series were performed by using simulated wind speed values in the range of $n_{\text {set }}=0.5 \mathrm{~Hz}\left(v^{*}=1.18 \mathrm{~m} / \mathrm{s}\right)$ to $n_{\text {set }}=25 \mathrm{~Hz}\left(v^{*}=6.97 \mathrm{~m} / \mathrm{s}\right)$ (Table 2).

Impact of the load regulation valve opening degree (hydraulic system load) on thermal power $P_{T l}$ on is presented in Figures 3 and 4 for simulated wind speeds of 1 to $4.5 \mathrm{~m} / \mathrm{s}$ and 4.5 to $7.0 \mathrm{~m} / \mathrm{s}$, respectively. It can be observed from the figures that the optimal opening degree of the load regulation valve $\gamma_{o p t}$ varies from 0.1 to 0.35 and depends on the simulated wind speed. 


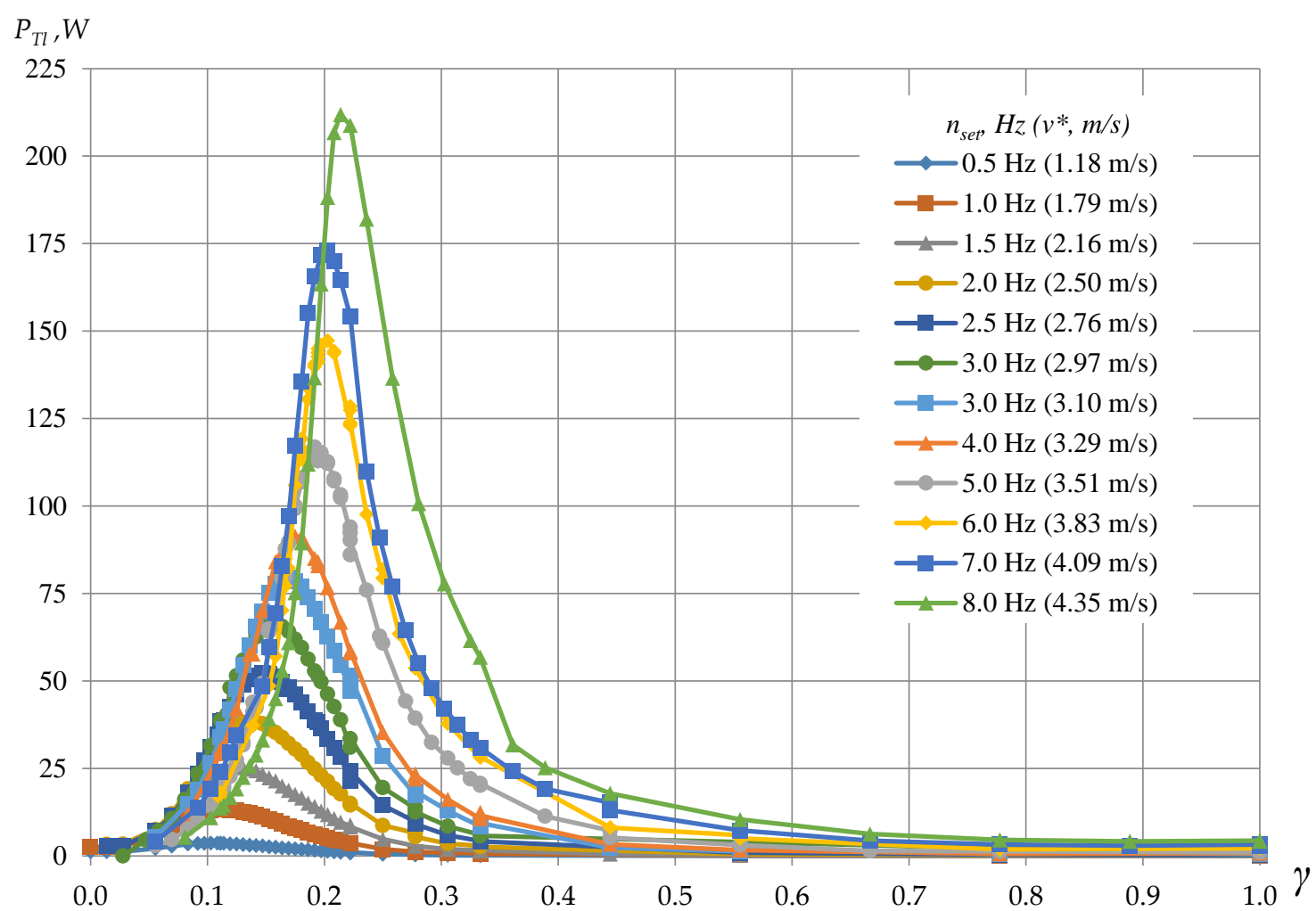

Figure 3. Thermal power $P_{T l}$ of the hydraulic system under variable opening degree $\gamma$ of the load regulation valve corresponding to the range of $n_{\text {set }}=0.5-8.0 \mathrm{~Hz}\left(v^{*}=1-4.5 \mathrm{~m} / \mathrm{s}\right)$.

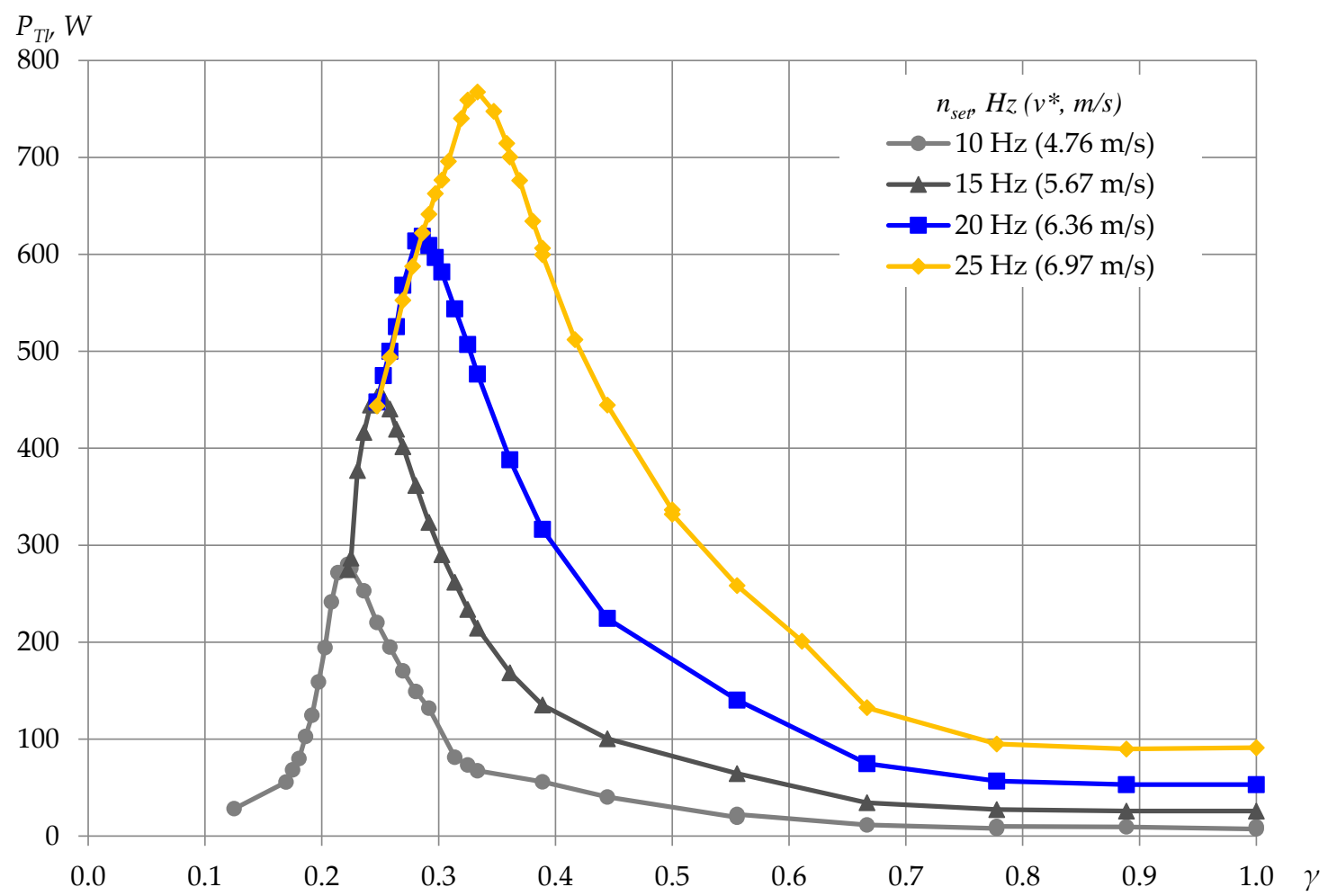

Figure 4. Thermal power $P_{T l}$ of the hydraulic system under variable opening degree $\gamma$ of the load regulation valve corresponding to the range of $n_{\text {set }}=10-25 \mathrm{~Hz}\left(v^{*}=4.5-7.0 \mathrm{~m} / \mathrm{s}\right)$. 
The optimal regime parameters $n_{\text {opt }}$ and $\gamma_{\text {opt }}$ were determined (Table 4$)$ for each value of $n_{\text {set }}\left(v^{*}\right)$.

Table 4. Main parameters of the hydraulic system working in the rated (optimal) regime.

\begin{tabular}{ccccccccc}
\hline$n_{\text {set }}, \mathrm{Hz}$ & 0.5 & 1 & 1.5 & 2 & 2.5 & 3 & 3.5 & 4 \\
\hline$v^{*}, \mathrm{~m} / \mathrm{s}$ & 1.18 & 1.79 & 2.16 & 2.50 & 2.76 & 2.97 & 3.10 & 3.29 \\
$\gamma_{\text {opt_20 }}{ }^{\circ} \mathrm{C}$ & 0.108 & 0.114 & 0.125 & 0.136 & 0.147 & 0.158 & 0.167 & 0.181 \\
$n_{\text {opt }}, \mathrm{Hz}$ & 0.28 & 0.57 & 0.90 & 1.23 & 1.56 & 2.01 & 2.27 & 2.79 \\
$P_{T l_{\perp} \max }, \mathrm{W}$ & 3.7 & 13.3 & 25.4 & 38.5 & 52.2 & 66.3 & 80.8 & 91.2 \\
$P_{T_{-} \text {max }}, \mathrm{W}$ & 4.4 & 15.4 & 26.5 & 41.9 & 56.1 & 69.1 & 79.8 & 95.1 \\
$\eta_{h s}$ & 0.94 & 0.95 & 0.93 & 0.94 & 0.94 & 0.93 & 0.94 & 0.94 \\
\hline$n_{\text {set }}, \mathrm{Hz}$ & 5 & 6 & 7 & 8 & 10 & 15 & 20 & 25 \\
$v^{*}, \mathrm{~m} / \mathrm{s}$ & 3.51 & 3.83 & 4.09 & 4.35 & 4.76 & 5.67 & 6.36 & 6.97 \\
$\gamma_{\text {opt_20 }}{ }^{\circ} \mathrm{C}$ & 0.192 & 0.203 & 0.203 & 0.214 & 0.222 & 0.247 & 0.286 & 0.333 \\
$n_{\text {opt }}, \mathrm{Hz}$ & 3.54 & 4.42 & 5.17 & 5.96 & 7.88 & 12.07 & 16.75 & 21.40 \\
$P_{\text {Tl_max }}, \mathrm{W}$ & 116.9 & 147.3 & 173.0 & 211.9 & 280.3 & 453.3 & 618.5 & 767.6 \\
$P_{T_{-} \text {max }}, \mathrm{W}$ & 115.8 & 151.9 & 181.9 & 220.0 & 289.5 & 483.1 & 664.2 & 881.9 \\
$\eta_{h s}$ & 0.95 & 0.95 & 0.94 & 0.94 & 0.95 & 0.93 & 0.91 & 0.92 \\
\hline
\end{tabular}

$n_{\text {set }}$ : electromotor shaft rotation frequency, $\mathrm{Hz} ; \mathrm{v}$ : wind velocity, $\mathrm{m} / \mathrm{s}$; $:$ wind velocity corresponding to $10 \mathrm{~m}^{2}$ swept area wind rotor with conversion efficiency of $0.45 ; \gamma$ : opening degree of the load regulation valve, dimensionless; $n$ : pump shaft rotation frequency, $\mathrm{Hz} ; P_{T l}$ : thermal power generated in load regulation valve, $\mathrm{W}$; $P_{T}$ : thermal power, $\mathrm{W} ; \eta_{h s}$ : hydraulic system efficiency for thermal energy conversion.

Both $n_{\text {opt }}$ and $\gamma_{\text {opt }}$ values were used to analyse the thermal power $P_{T}$ (Equation (6)) by the measured temperatures in the return pipe $T_{\text {out }}$ (after heat exchanger) and oil temperature $T_{r}$ in the oil tank (the average value of three thermometers). The thermal power $P_{T}$ reached its peak values at the same pump's shaft rotation frequency $n$ (Figures 5 and 6 ). This result proves that the heat generation ability of the system can be used as an indicator to identify the parameters of its optimal performance.

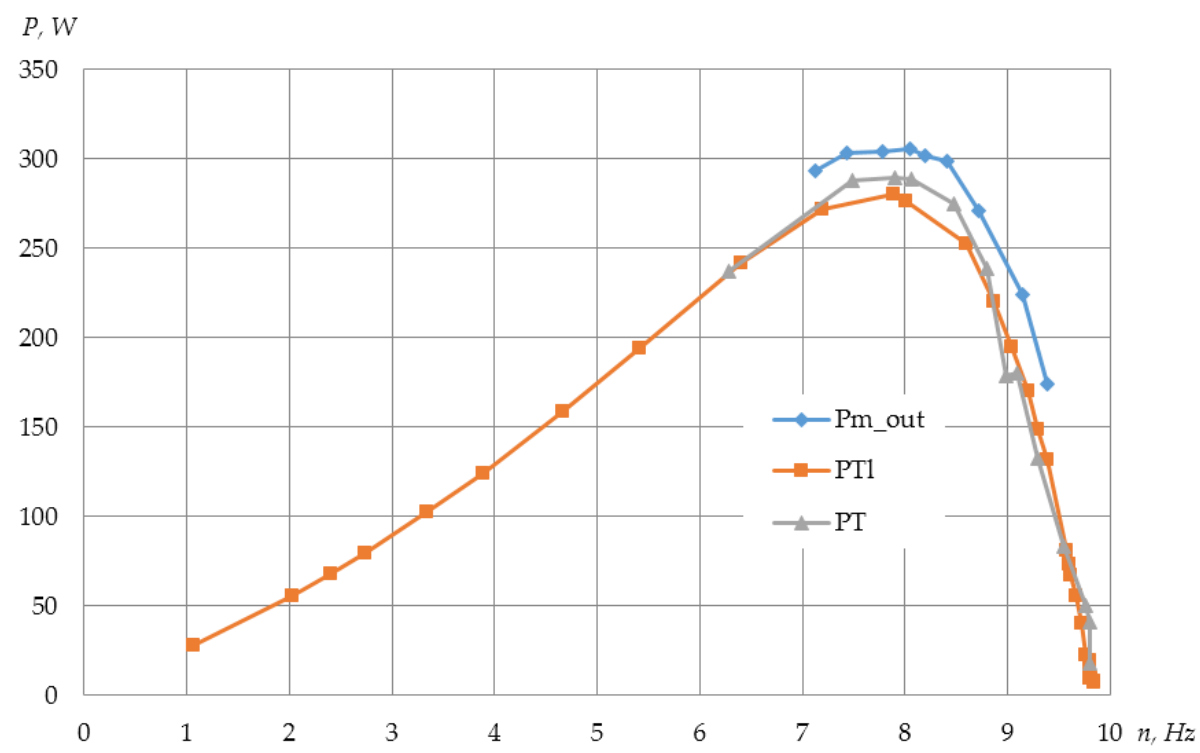

Figure 5. Influence of the pump's shaft rotation frequency $n$ on the generated power $P$ at $n_{\text {set }}=10 \mathrm{~Hz}$. 


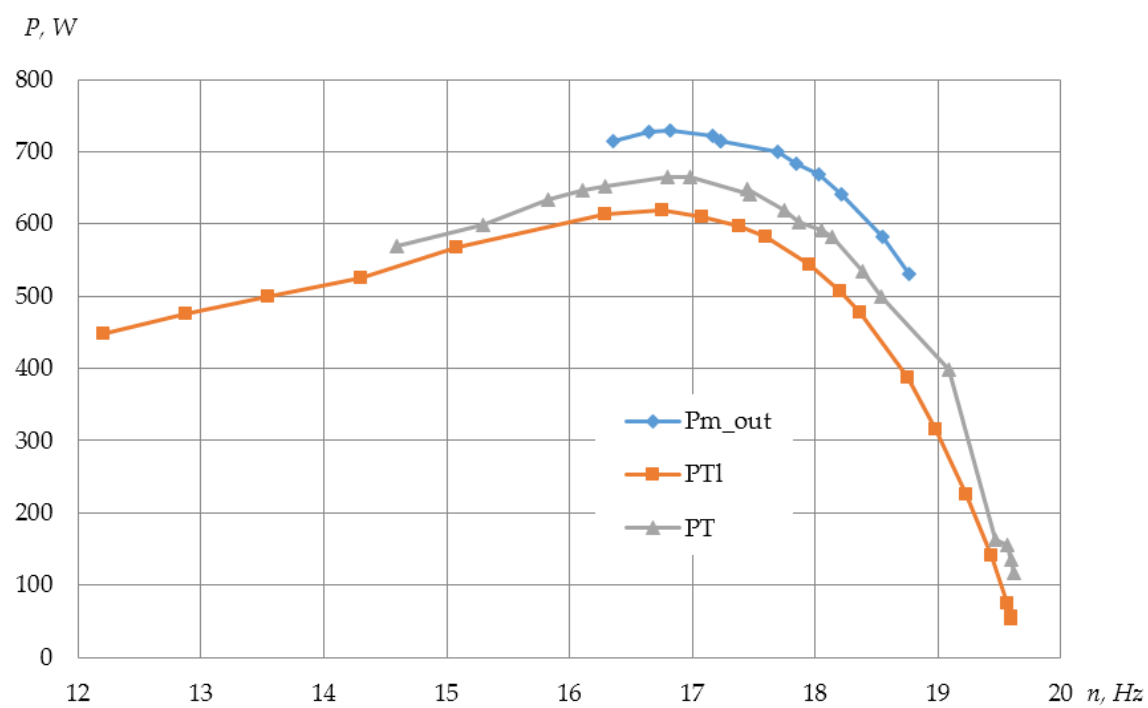

Figure 6. Influence of the pump's shaft rotation frequency $n$ on the generated power $P$ at $n_{\text {set }}=20 \mathrm{~Hz}$.

According to the results of the experimental study (Figure 7), heat generation potential by adjusting the load regulation valve $\left( \pm \Delta P_{T_{-} \max }<2.5 \%\right)$, can be quantified using the following empirical equation:

$$
P_{T \_\max }=2.80 *^{3}
$$

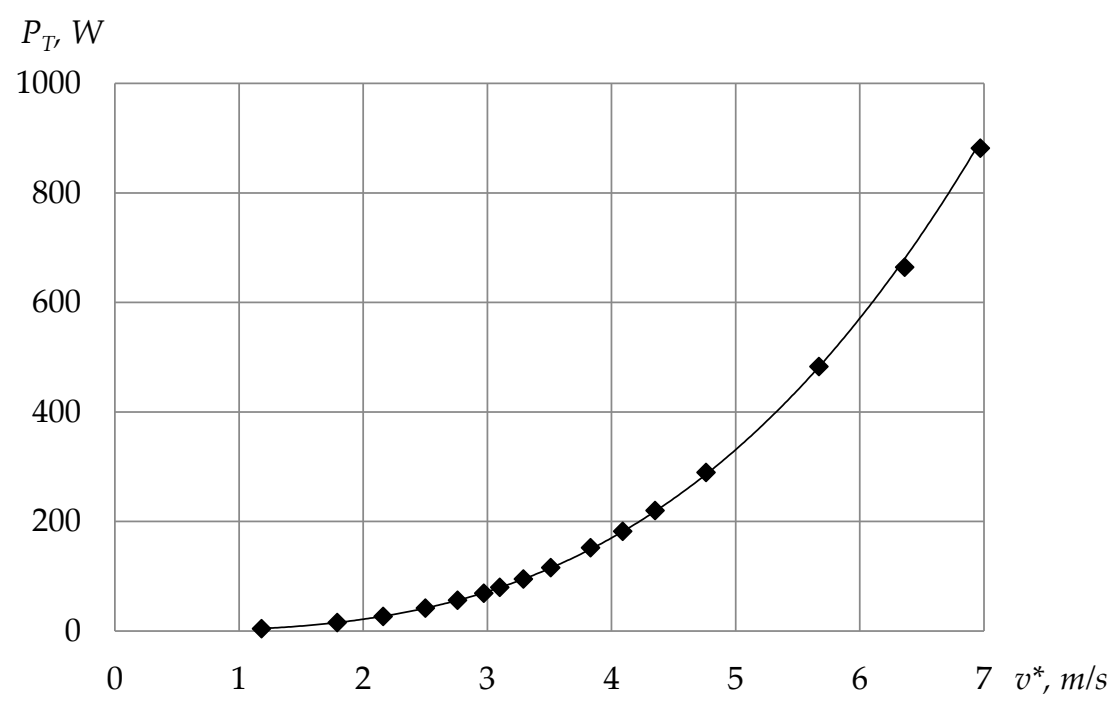

Figure 7. Influence of simulated wind speed* at 1 to $7 \mathrm{~m} / \mathrm{s}$ range on thermal power $P_{T}$ of the hydraulic system.

The following equation (Figure 8) can be used to determine optimal working regime of the analysed system:

$$
n_{o p t}=0.03 v *^{3}+0.32 v *^{2}-0.72 v *+0.63
$$

The percentage error of $n_{\text {opt }}$ obtained by Equation 12 is less than $\pm 10 \%$ within the interval of wind speed $v^{*}$ from 1.18 to $4 \mathrm{~m} / \mathrm{s}$ and less than $\pm 2.5 \%$ within the interval from 4 to $7 \mathrm{~m} / \mathrm{s}$. 


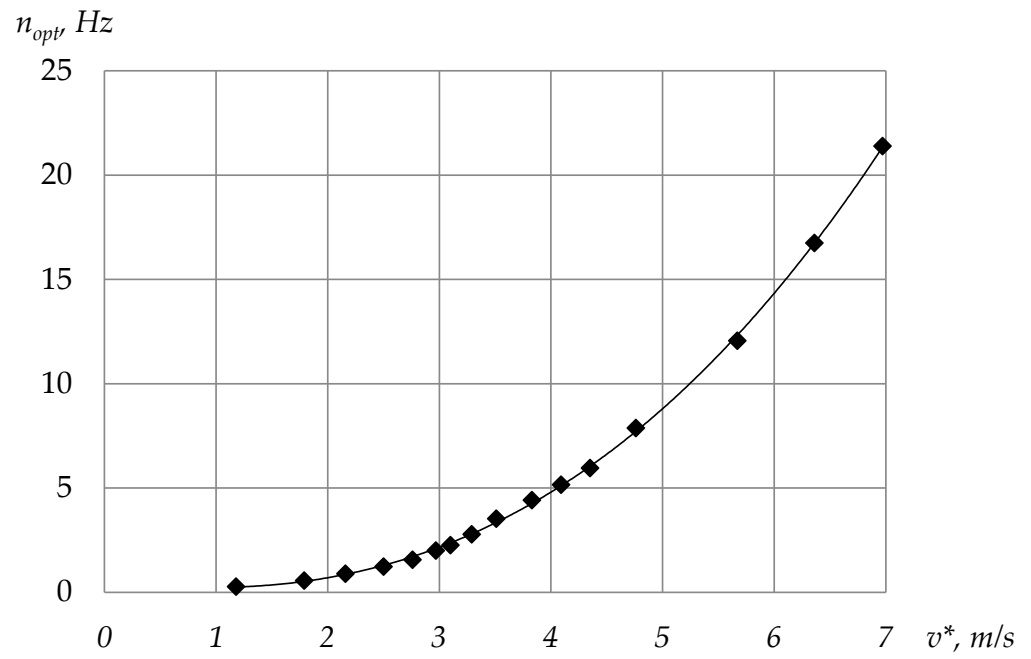

Figure 8. Influence of simulated wind speed* at 1 to $7 \mathrm{~m} / \mathrm{s}$ range on optimal hydraulic pump rotation frequency.

\subsection{Analysis of the Automatic Control of the System}

The optimal rotation frequency of the hydraulic pump must be determined to synchronise wind rotor performance with the hydraulic system. Optimal rotation frequency $n_{r}$ is required from the wind rotor side to reach optimal wind speed difference before and after wind rotor, as well as to obtain optimal wind rotor performance for different wind speeds. Optimising the hydraulic pump rotation frequency $n$ is required to reach the peak point in thermal energy generation. As the rotation frequencies of the wind rotor shaft and the hydraulic pump shaft do not conform, the transmission system is necessary. The impact of the opening degree $\gamma$ of load regulation valve on the pump's shaft rotation frequency $n$ is provided in Figure 9 .

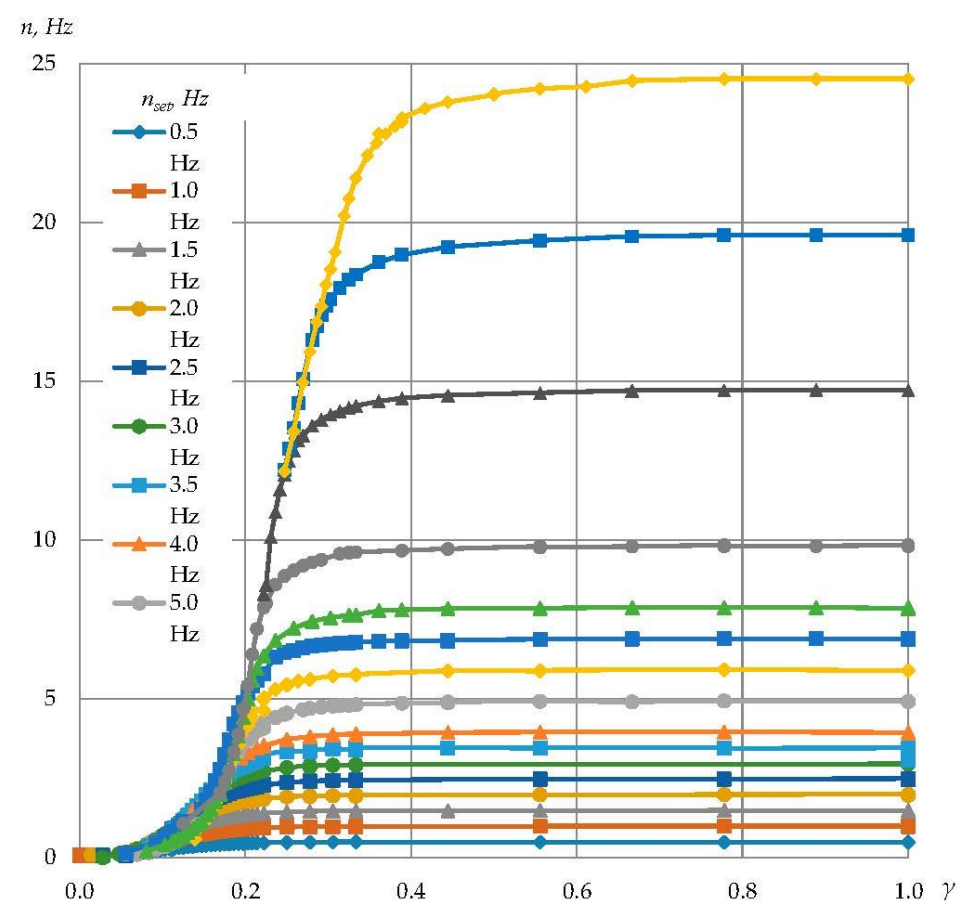

Figure 9. Influence of opening degree $\gamma$ of the load regulation valve in the range of $n_{\text {set }}=10-25 \mathrm{~Hz}$ $\left(v^{*}=4.5-7.0 \mathrm{~m} / \mathrm{s}\right)$ on the pump's shaft rotation frequency $n$. 
The experimental results provided in Figures 3-5 show that $P_{T l}=f(\gamma)$ and $\gamma=f(v)$. However, automatic control of the wind driven hydraulic system must be applied to synchronize wind rotor, hydraulic system and transmission system as both efficiency and overall performance of the hydraulic system depends on the pump's shaft rotation frequency $n$. For instance, $P_{T l}=f(\gamma)$ for $n_{\text {set }}=25 \mathrm{~Hz}$ shows that maximum heat generation performance $\left(P_{T l}=767.6 \mathrm{~W}\right)$ can be obtained at $\gamma=0.333$ (Figure 4 ). The $n=f(\gamma)$ function provided in Figure 9 and $P_{T l}=f(n)$ function provided in Figure 10 shows that this $P_{T I}$ value is reached at $n=21.4 \mathrm{~Hz}$. Nevertheless, this rotation frequency is not optimal from the point of view of wind rotor-transmission-hydraulic unit system efficiency. Generalized results of the tested hydraulic system performance are presented in Figure 10, and shows the influence of hydraulic system rotation frequency on thermal energy generation.

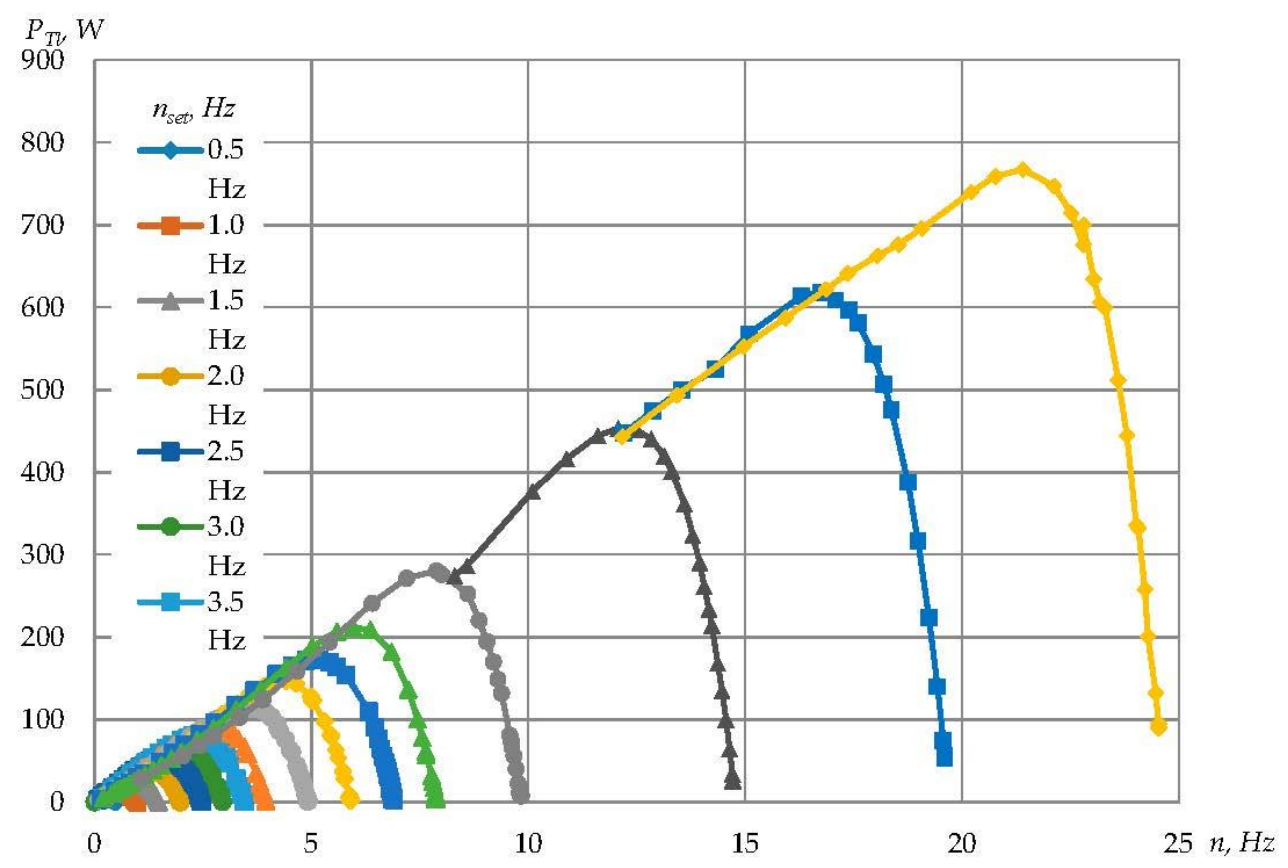

Figure 10. Influence of the hydraulic pump's shaft rotation frequency $n$ in the range of $n_{\text {set }}=10-25 \mathrm{~Hz}$ $\left(v^{*}=4.5-7.0 \mathrm{~m} / \mathrm{s}\right)$ on thermal power $P_{T l}$.

Performance of the hydraulic system depends on kinematic viscosity of the oil, which, in turn, is a function of the oil temperature in the system. Therefore, an additional set of experiments was carried out to estimate this impact at two pump's shaft rotation frequencies- $n_{\text {set }}=10 \mathrm{~Hz}$ and $n_{\text {set }}=20 \mathrm{~Hz}$, corresponding to wind speeds of $4.76 \mathrm{~m} / \mathrm{s}$ and $6.36 \mathrm{~m} / \mathrm{s}$, respectively. The results of the measurements are presented in Figures 11 and 12. It showed that the system is more sensitive to oil temperature variation at lower wind speeds as wider distribution of values were obtained in the case of $n_{\text {set }}=10 \mathrm{~Hz}$, compared to $n_{\text {set }}=20 \mathrm{~Hz}$ case.

The impact of oil temperature in the range from $20^{\circ} \mathrm{C}$ to $50{ }^{\circ} \mathrm{C}$ on optimal parameters, defined in Table 3, was relatively low. Nevertheless, $n_{\text {opt }}$ should be automatically maintained to maximise thermal energy generation by adjusting the opening degree $\gamma$ of the load regulation valve. 


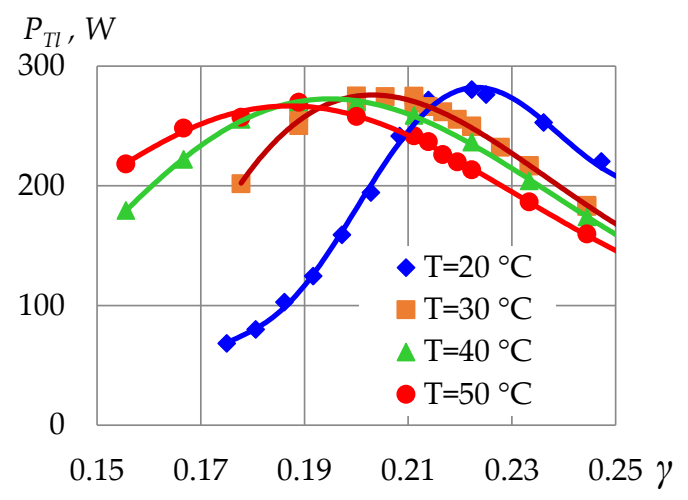

Figure 11. Dependence of the load control valve optimal opening degree $\gamma_{\text {opt }}$ on the oil temperature for $n_{\text {set }}=10 \mathrm{~Hz}$.

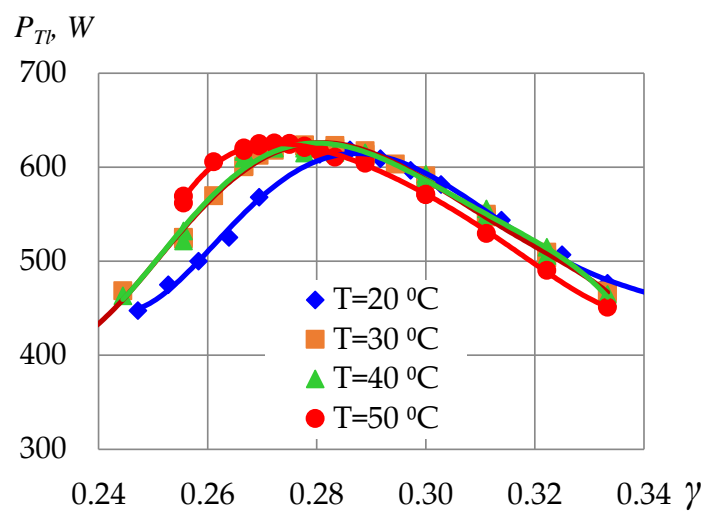

Figure 12. Dependence of the load control valve optimal opening degree $\gamma_{o p t}$ on the oil temperature for $n_{\text {set }}=20 \mathrm{~Hz}$.

\section{Discussion}

The goals to mitigate climate change and reach the EU "20-20-20 by 2020" targets relies highly on renewable energy technologies [29]. Transition to zero carbon society is linked to increasing energy access and economic independence, jobs creation, human health and wellbeing. However, barriers to this transition, such as people's resistance to change, inadequate information or even cultural reasons, should not be neglected $[30,31]$. Technology of direct wind conversion into heat discussed in this paper, should contribute to this transition. It has a potential of being both replicable small-scale and socially acceptable solutions compared to large-scale installations, e.g., wind farms. Possibilities to integrate such systems with shallow and deep geothermal applications should be analysed as well. Heat pump technology is already well accepted among users and when combined with wind generated heat supply systems, more stable technical solutions can be achieved.

Usually different zero carbon future scenarios agree on the necessity to use different types of renewable energy conversion technologies that allows creating smart and efficient energy grids [32-34]. Upscaled to a medium-size application, direct wind energy conversion into heat can be implemented on the neighbourhood scale.

The technology presented in this paper is especially relevant for moderate and cold climate countries, which were affected by fast urbanisation after WWII. Majority of the building stocks in such countries consist of buildings of low energy efficiency [35]. Baltic states-Lithuania, Latvia and Estonia-are quite representative examples due to similar climate conditions and a high number of apartment blocks built during the 1970s and the 1980s [36-38]. Continuous state support for renewable energy implementation technologies seems to be necessary in all Baltic states [39]. However, statistics 
shows that the most intensive support from the EU Structural Funds is aimed to increase biomass applications, while solar and wind energy conversion received much less funding [40].

Approximate calculations showed that implementation of the technology discussed in this paper has a high potential in reducing $\mathrm{CO}_{2}$ emissions on the neighbourhood scale. Wind power plant of $2 \mathrm{~kW}$ heating capacity installed in typical residential building could reduce $\mathrm{CO}_{2}$ emissions by up to $70 \%$ when compared to natural gas applications. Compared to district heating applications, up to $65 \%$ lower $\mathrm{CO}_{2}$ emissions can be achieved due to the fact that the share of biomass has increased in the district heating networks within the past decade [41]. These savings are subject to wind speeds in urban neighbourhoods and the installation itself.

The results presented in this paper are focused on delivering the proof of concept from the perspective of operation and thermal energy output generated by the prototype unit. The hydraulic system itself was not connected to the wind turbine, and the mechanical wind energy was simulated by using the electromotor. However, such design of the experiment allowed testing the system at stable rotation frequencies and precisely controlled operation modes.

Performance of the analysed system depends on optimisation of the opening degree of the load regulation valve $\gamma$. Integrated approach should be applied to ensure that the system is running at the $n_{\text {opt }}$ mode, such as measuring the wind speed and adjusting the opening degree of the load regulation valve by using an electric drive. Therefore, the pump should be loaded by changing the flow resistance of the hydraulic system. Tachometer should be integrated in the system to measure the rotation frequency of the pump shaft $n$, and the control algorithm should be applied to modify the opening degree of the load regulation valve, as well as to keep it at the optimal level $n_{\text {opt }}$. The scheme of the proposed control system is presented in Figure 13.

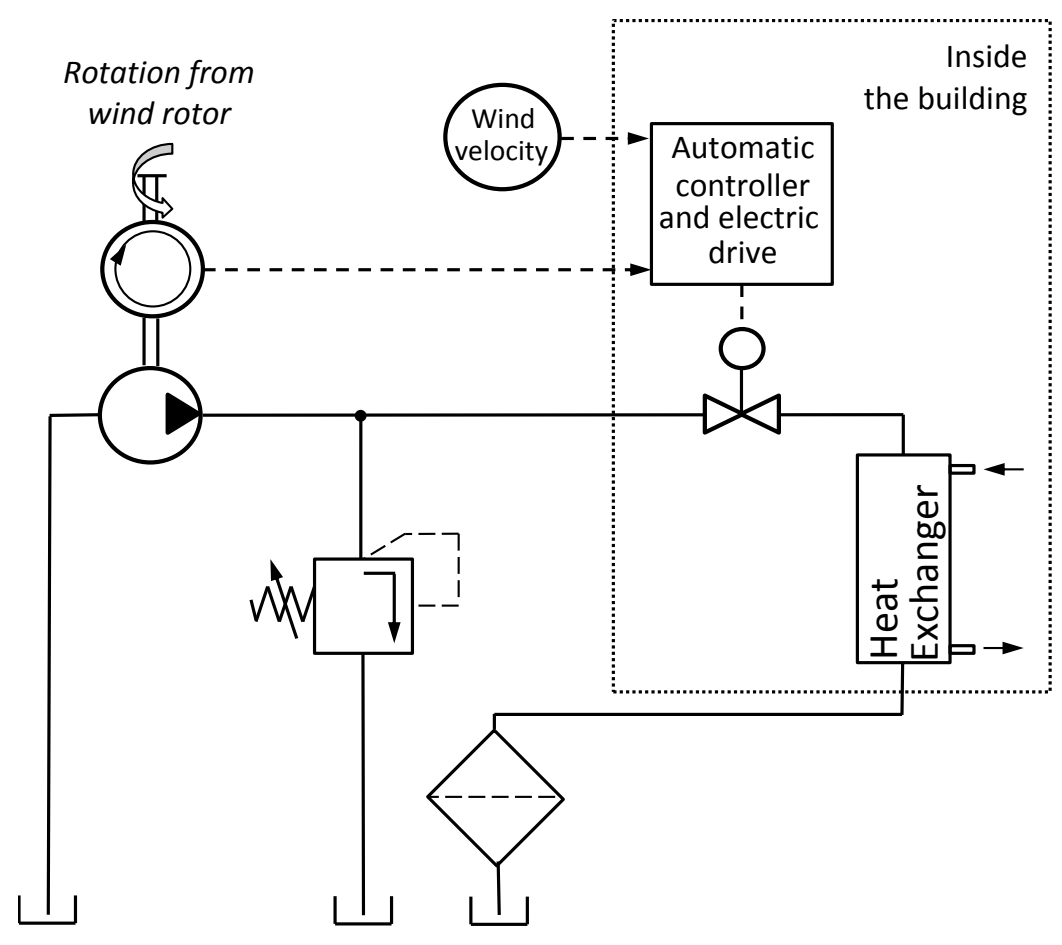

Figure 13. Automatic control scheme of the hydraulic system for mechanical wind energy conversion into heat.

Hydraulic accumulator can be introduced to increase steadiness of the hydraulic system performance. It would also be beneficial to test the application of the axial flow variable displacement piston pump coupled with the flow restrictor, instead of the gear pump and load regulation valve, which were used in this study. It is probable, that such a system would work steadier and would 
reduce the need of the automatic controller and the electric drive. However, the loading of such systems might become more complicated.

Heat losses from the analysed hydraulic system should be minimised to increase the efficiency of the system (Equation (10)). Therefore, thermal insulation should be installed on the piping, the pump itself or the oil tank with the pump submerged in it. The temperature of the oil will reduce as it passes through the heat exchanger, protecting the thermally insulated pump from overheating. The pressure pipe can be built in the return pipe to decrease of heat losses as well. The distance between the pump driven by the wind rotor and the heat exchanger should be minimised.

In case a heat accumulation tank is integrated in such a system, high thermal resistance materials should be used to minimise heat losses. Polyurethane foam is a good example of hot water storage tank insulation, which is already widely used in similar applications. Storing thermal energy outside can also be a viable option, especially when combined with ground source heat pump.

Other technologies, such as wind driven hydraulic mixing, can also be applied to convert mechanical wind energy into heat [42,43]. It should be noted that one of the main purposes of this study was to refresh and intensify the discussion of hydraulic applications for direct conversion of mechanical wind energy into heat. Availability of such small-scale applications could play a significant role in stimulating the "bottom-up" approach in renewable energy promotion, and become a replicable solution in the Baltic States region as well as other moderate and cold climate European countries at urban wind velocities. Hydraulic systems used in conjunction with other renewables, e.g., solar thermal, photovoltaic systems, should contribute to the transition to zero carbon built environment on the regional scale.

\section{Conclusions}

Wind as one of the renewable energy resource thus far is used only for producing electricity. However, it's known but almost forgotten that hydraulic systems can be used for conversion of wind mechanical energy to thermal without producing the electricity.

In the case of wind mechanical energy conversion to electricity the heat emission means the energy losses. The final product and the losses are the same types of energy in the case of hydraulic system for conversion of wind mechanical energy into the heat. Thermal insulation of some system components and other engineering solutions allow managing and decreasing to minimum the heat losses to outside and increase the efficiency of such hydraulic system to almost maximal possible value: $\eta \rightarrow 1$.

Possibilities of the hydraulic energy conversion system characterised as non-complex, collected from the standard elements was researched experimentally. An optimal work regime of system was reached by changing the opening degree of load control valve from 0.1 to 0.33 for values of wind velocity from 1 to $7 \mathrm{~m} / \mathrm{s}$. It was determined the dependence between the optimal rotation frequency of the loaded hydraulic pump shaft and the wind velocity. Such dependence can be used for automatic control of the work of the hydraulic system as energy converter in small wind velocity range.

Author Contributions: Tadas Zdankus and Jurgita Cerneckiene developed research ideas and experimental methodology, and collected the data. All co-authors developed a discussion chapter, analysed the data and provided a thorough review to enhance the overall quality of this paper.

Conflicts of Interest: The authors declare no conflict of interest. 


\section{Nomenclature}

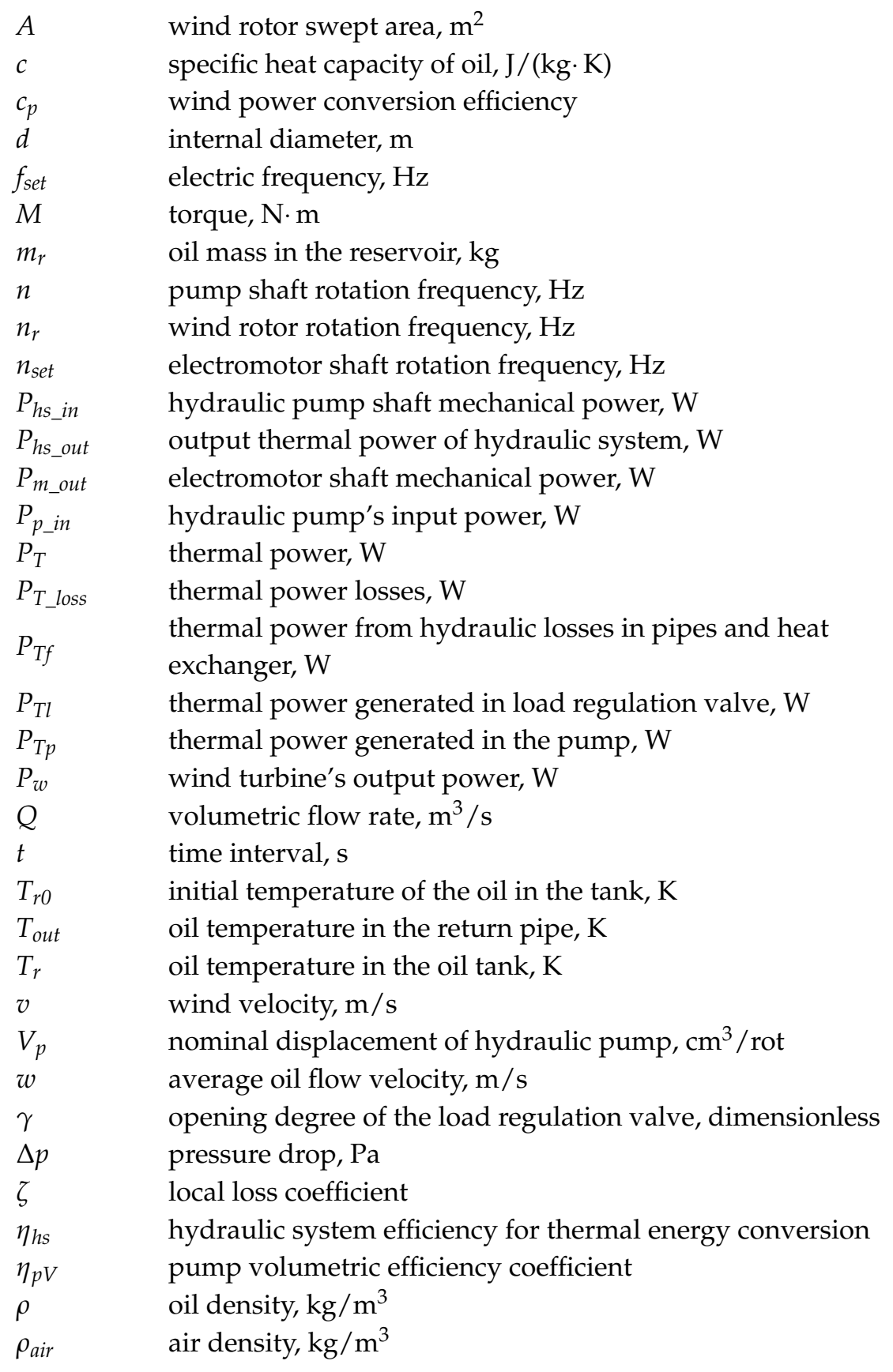

\section{References}

1. European Wind Energy Association (EWEA). Wind in Power: 2015 European Statistics. Available online: http:/ /www.ewea.org/fileadmin/files/library/publications/statistics/EWEA-Annual-Statistics2015.pdf (accessed on 15 April 2016).

2. United Nations Conference on Climate Change. Available online: http://www.cop21.gouv.fr/en/ (accessed on 15 December 2015).

3. United Nations. Framework Convention on Climate Change 1992. Available online: https://unfccc.int (accessed on 15 April 2016).

4. Cheng, M.; Zhu, Y. The state of the art of wind energy conversion systems and technologies: A review. Energy Convers. Manag. 2014, 88, 332-347. [CrossRef] 
5. Tummala, A.; Velamati, R.K.; Sinha, D.K.; Indraja, V.; Krishna, V.H. A review on small scale wind turbines. Renew. Sustain. Energy Rev. 2016, 56, 1351-1371. [CrossRef]

6. Ishugah, T.F.; Li, Y.; Wang, R.Z.; Kiplagat, J.K. Advances in wind energy resource exploitation in urban environment: A review. Renew. Sustain. Energy Rev. 2014, 37, 613-626. [CrossRef]

7. Miškinis, V. Lietuvos energetika / Energy in Lithuania 2013; Lithuanian Energy Institute: Kaunas, Lithuania, 2014.

8. International Energy Data and Analysis-Lithuania. Available online: http://www.eia.gov/ (accessed on 10 January 2016).

9. European Parliament, Council of the European Union. EU Directive 2010/31/EU of the European Parliament and of the Council of 19 May 2010 on the energy performance of buildings (recast). Off. J. Eur. Union 2010, 153, 13-35.

10. Olatomiwa, L.; Mekhilef, S.; Ismail, M.S.; Moghavvemi, M. Energy management strategies in hybrid renewable energy systems: A review. Renew. Sustain. Energy Rev. 2016, 62, 821-835. [CrossRef]

11. Del Granado, P.C.; Pang, Z.; Wallace, S.W. Synergy of smart grids and hybrid distributed generation on the value of energy storage. Appl. Energy 2016, 170, 476-488. [CrossRef]

12. Lott, M.C.; Kim, S.-I. Technology Roadmap: Energy Storage; International Energy Agency: Paris, France, 2014.

13. Fazlollahi, S.; Schüler, N.; Maréchal, F. A solid thermal storage model for the optimization of buildings operation strategy. Energy 2015, 88, 209-222. [CrossRef]

14. Okazaki, T.; Shirai, Y.; Nakamura, T. Concept study of wind power utilizing direct thermal energy conversion and thermal energy storage. Renew. Energy 2015, 83, 332-338. [CrossRef]

15. Černeckienė, J. Usage of the Wind Energy for Heating of the Energy-Efficient Buildings: Analysis of Possibilities. J. Sustain. Archit. Civ. Eng. 2015, 10, 58-65. [CrossRef]

16. Knecht, J.E. Wind Driven Heating System. 1983, p. 8. Available online: https://www.google.ch/patents / US4366779 (accessed on 15 May 2016).

17. Ashiklan, B. Wind Motor Operated Heating System. 1973, p. 5. Available online: https://www.google.ch/ patents/US3752395 (accessed on 15 May 2016).

18. Ashiklan, B. Wind Operated Heating System. 1974, p. 6. Available online: https://www.google.com/ patents/US3783858 (accessed on 15 May 2016).

19. RISØ. The UNDP/GEF Baltic Wind Atlas; Risø National Laboratory: Roskilde, Denmark, 2003; Volume 1402.

20. Troen, I.; Petersen, E.L. European Wind Atlas; Risø National Laboratory: Roskilde, Denmark, 1989.

21. Žiedelis, S. Hydraulic and Pneumatic Systems; Technologija: Kaunas, Lithuania, 2009.

22. Johnson, R.W. The Handbook of Fluid Dynamics; Springer-Verlag GmbH \& Co: Berlin, Germany, 2000.

23. Street, R.L.; Watters, G.Z.; Vennard, J.K. Elementary Fluid Mechanics; John Wiley \& Sons: Toronto, ON, Canada, 1996.

24. Huang, S.-C.; Lo, S.-L.; Lin, Y.-C. To Re-Explore the Causality between Barriers to Renewable Energy Development: A Case Study of Wind Energy. Energies 2013, 6, 4465-4488. [CrossRef]

25. Jianu, O.; Rosen, M.A.; Naterer, G. Noise pollution prevention in wind turbines: Status and recent advances. Sustainability 2012, 4, 1104-1117. [CrossRef]

26. Mathew, S. Wind Energy: Fundamentals, Resources Analysis and Economics; Springer: Berlin, Germany, 2006.

27. Climatology Division at Lithuanian Hydrometeorological Service under the Ministry of Environment. Climate averages for Lithuania 1981-2010. 2013. Available online: http://www.meteo.lt/documents/20181/ 103901/Lietuvos_klimatas_09_25.pdf/e307f875-d20b-4a4d-aa90-c66a4dd57885 (accessed on 15 May 2016).

28. Jacobs, P. Thermodynamics; Imperial College Press: London, UK, 2013.

29. Commission of the European Communities. Action Plan for Energy Efficiency: Realising the Potential. 2006. Available online: http://eur-lex.europa.eu/legal-content/EN/TXT/PDF/?uri=CELEX: 52006DC0545\&from=EN (accessed on 15 May 2016).

30. Rosso-Cerón, A.M.; Kafarov, V. Barriers to social acceptance of renewable energy systems in Colombia. Curr. Opin. Chem. Eng. 2015, 10, 103-110. [CrossRef]

31. Painuly, J.P. Barriers to renewable energy penetration: A framework for analysis. Renew. Energy 2001, 24, 73-89. [CrossRef]

32. Tokimatsu, K.; Konishi, S.; Ishihara, K.; Tezuka, T. Global zero emission scenario: Role of innovative technologies. Energy Procedia 2014, 61, 164-167. [CrossRef]

33. Tokimatsu, K.; Konishi, S.; Ishihara, K.; Tezuka, T.; Yasuoka, R.; Nishio, M. Role of innovative technologies under the global zero emissions scenarios. Appl. Energy 2014, 162, 1483-1493. [CrossRef] 
34. Yuan, H.; Zhou, P.; Zhou, D. What is low-carbon development? A conceptual analysis. Energy Procedia 2011, 5, 1706-1712. [CrossRef]

35. Brauers, W.K.M.; Kracka, M.; Zavadskas, E.K. Lithuanian case study of masonry buildings from the Soviet period. J. Civ. Eng. Manag. 2012, 18, 444-456. [CrossRef]

36. Denafas, G.; Sitnikovas, D.; Galinis, A.; Kudrenickis, I.; Klavs, G.; Kuusik, R. Predicting $\mathrm{CO}_{2}$ and $\mathrm{SO}_{2}$ emissions in the Baltic States through reorganization of energy infrastructure. Environ. Int. 2004, 30, 1045-1053. [CrossRef] [PubMed]

37. Roos, I.; Soosaar, S.; Volkova, A.; Streimikene, D. Greenhouse gas emission reduction perspectives in the Baltic States in frames of EU energy and climate policy. Renew. Sustain. Energy Rev. 2012, 16, 2133-2146. [CrossRef]

38. Streimikiene, D.; Balezentis, T. Kaya identity for analysis of the main drivers of GHG emissions and feasibility to implement EU “20-20-20" targets in the Baltic States. Renew. Sustain. Energy Rev. 2016, 58, 1108-1113. [CrossRef]

39. Blumberga, A.; Lauka, D.; Barisa, A.; Blumberga, D. Modelling the Baltic power system till 2050. Energy Convers. Manag. 2016, 107, 67-75. [CrossRef]

40. Streimikienè, D. Review of financial support from EU Structural Funds to sustainable energy in Baltic States. Renew. Sustain. Energy Rev. 2016, 58, 1027-1038. [CrossRef]

41. Lithuanian Ministry of Environment. STR 2.01.09:2012 The energy efficiency in buildings, The energy certification of buildings, Lithuanian building regulations. 2012. Available online: http://www3.lrs.lt/pls / inter3/dokpaieska.showdoc_l?p_id=431646\&p_query=\&p_tr2=2 (accessed on 15 May 2016).

42. Thompson, J.W.; Freeman, P.A. Wind-Powered Impeller-Mixer. Patents US 4292540 A, 29 September 1980.

43. Kavolynas, A. Application of solar and wind energy. Ph.D. Thesis, Aleksandras Stulginskis University, Akademija, Lithuania, 2011.

(C) 2016 by the authors; licensee MDPI, Basel, Switzerland. This article is an open access article distributed under the terms and conditions of the Creative Commons Attribution (CC-BY) license (http://creativecommons.org/licenses/by/4.0/). 